\title{
Trends of limb amputation considering type, level, sex and age in Saskatchewan, Canada 2006-2019: an in-depth assessment
}

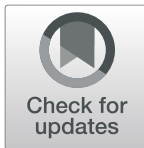

\author{
Samuel Kwaku Essien ${ }^{1 *}$ D, David Kopriva ${ }^{2,3}$, A. Gary Linassi ${ }^{4}$ and Audrey Zucker-Levin ${ }^{1}$
}

\begin{abstract}
Background: Most epidemiologic reports focus on lower extremity amputation (LEA) caused specifically by diabetes mellitus. However, narrowing scope disregards the impact of other causes and types of limb amputation (LA) diminishing the true incidence and societal burden. We explored the rates of LEA and upper extremity amputation (UEA) by level of amputation, sex and age over 14 years in Saskatchewan, Canada.

Methods: We calculated the differential impact of amputation type (LEA or UEA) and level (major or minor) of LA using retrospective linked hospital discharge data and demographic characteristics of all LA performed in Saskatchewan and resident population between 2006 and 2019. Rates were calculated from total yearly cases per yearly Saskatchewan resident population. Joinpoint regression was employed to quantify annual percentage change (APC) and average annual percent change (AAPC). Negative binomial regression was performed to determine if LA rates differed over time based on sex and age.

Results: Incidence of LEA $(31.86 \pm 2.85$ per 100,000) predominated over UEA $(5.84 \pm 0.49$ per 100,000) over the 14year study period. The overall LEA rate did not change over the study period (AAPC -0.5 [95\% Cl -3.8 to 3.0$]$ ) but fluctuations were identified. From 2008 to 2017 LEA rates increased (APC 3.15 [95\% Cl 1.1 to 5.2]) countered by two statistically insignificant periods of decline (2006-2008 and 2017-2019). From 2006 to 2019 the rate of minor LEA steadily increased (AAPC 3.9 [95\% Cl 2.4 to 5.4]) while major LEA decreased (AAPC -0.6 [95\% Cl - 2.1 to 5.4]). Fluctuations in the overall LEA rate nearly corresponded with fluctuations in major LEA with one period of rising rates from 2010 to 2017 (APC 4.2 [95\% Cl 0.9 to 7.6]) countered by two periods of decline 2006-2010 (APC -11.14 [95\% Cl - 16.4 to -5.6$]$ ) and 2017-2019 (APC -19.49 [95\% Cl - 33.5 to -2.5$]$ ). Overall UEA and minor UEA rates remained stable from 2006 to 2019 with too few major UEA performed for in-depth analysis. Males were twice as likely to undergo $L A$ than females ( $R R=2.2[95 \% \mathrm{Cl} 1.99-2.51])$ with no change in rate over the study period. Persons aged 50-74 years and 75+ years were respectively $5.9(\mathrm{RR}=5.92[95 \% \mathrm{Cl} 5.39-6.51])$ and $10.6(\mathrm{RR}=10.58$ [95\% Cl 9.26-12.08]) times more likely to undergo LA than those aged 0-49 years. LA rate increased with increasing age over the study period.
\end{abstract}

\footnotetext{
*Correspondence: sam.essien@usask.ca

'School of Rehabilitation Science, University of Saskatchewan, Health Science Building, E-Wing, Suite 3400, 3rd Floor, 104 Clinic Place, Saskatoon, SK S7N 2Z4, Canada

Full list of author information is available at the end of the article
}

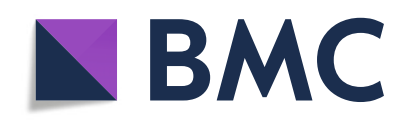

(c) The Author(s). 2021 Open Access This article is licensed under a Creative Commons Attribution 4.0 International License, which permits use, sharing, adaptation, distribution and reproduction in any medium or format, as long as you give appropriate credit to the original author(s) and the source, provide a link to the Creative Commons licence, and indicate if changes were made. The images or other third party material in this article are included in the article's Creative Commons licence, unless indicated otherwise in a credit line to the material. If material is not included in the article's Creative Commons licence and your intended use is not permitted by statutory regulation or exceeds the permitted use, you will need to obtain permission directly from the copyright holder. To view a copy of this licence, visit http://creativecommons.org/licenses/by/4.0/ The Creative Commons Public Domain Dedication waiver (http://creativecommons.org/publicdomain/zero/1.0/) applies to the data made available in this article, unless otherwise stated in a credit line to the data. 
Conclusion: The rise in the rate of minor LEA with simultaneous decline in the rate of major LEA concomitant with the rise in age of patients experiencing LA may reflect a paradigm shift in the management of diseases that lead to LEA. Further, this shift may alter demand for orthotic versus prosthetic intervention. A more granular look into the data is warranted to determine if performing minor LA diminishes the need for major LA.

Keywords: Epidemiology, Incidence, Amputation, Lower extremity, Upper extremity

\section{Background}

Limb amputation (LA) is a life-changing procedure that impacts physical function and imposes economic burden on patients, caregivers, and the healthcare system [1-5]. Most epidemiologic reports focus on lower extremity amputation (LEA) caused by dysvascular disease, specifically diabetes mellitus (DM) [6, 7]. This focus is important to determine intervention efficacy and for predication purposes [8-10]; however, narrowing scope disregards the impact of other causes and types of LA diminishing the true incidence and societal burden.

Exploring LA incidence rates and trends over time can improve future tracking [11] and identify if a more rigorous investigation into inherent cause is needed $[6,12$, 13]. Further, understanding trends in demographics of people living with LA can assist with identifying future orthotic, prosthetic and health service needs. For example, a rise in minor LA rate may demand more orthotic intervention such as custom insoles with toe fillers, while a rise in major LA may increase demand for prosthetic intervention. There are no previously published reports characterizing the entire cohort of people affected by LA in Saskatchewan, limiting comparison to other Provinces and countries. This study aimed to (1) assess the differential impact of lower and upper extremity amputation on LA incidence in Saskatchewan, and (2) explore overall amputation incidence rate by demographic profile in Saskatchewan and compare it with other Canadian trends.

\section{Methods}

\section{Data sources}

This study used hospital discharge data on all limb amputations (LA) over a 14-year period (2006-2019) performed in Saskatchewan and stipulated in the Canadian Classification of Health Interventions (CCI) codes (1SN93, 1SQ93, 1TA93, 1TK93, 1TM93, 1TV93, 1VA93, 1VC93, 1VG93, 1VQ93, 1UB93, 1UE93, 1UF93, 1UG93, 1UH93, 1UI93, 1UT93, 1UK93, 1UM93, 1WA93, 1WE93, 1WI93, 1WJ93, 1WK93, 1WL93, 1WM93, 1WN93) (see supplementary file 1) [14]. This Discharge Abstract Database (DAD) is located at eHealth Saskatchewan accessible via Saskatchewan Health Quality Council. The DAD included all hospitals and health facilities in the province of Saskatchewan and contains up to 25 diagnoses and 20 interventions per hospitalization and is de- identifiably merged, by unique Saskatchewan personal health insurance numbers, to the Person Health Registration System. This enabled the extraction of matching demographic characteristics as stipulated in the provincial health insurance plan.

Subjects discharged for all causes of LA between January 1, 2006, and December 31, 2019 were included in the study. Type of amputation (upper extremity/lower extremity) were categorized by level as major (through/proximal to the ankle/wrist) or minor (distal to the ankle/ wrist) based on CCI procedure codes [15]. If more than one LA was identified during the same hospitalization, the highest level LA was considered for analysis. If both UEA and LEA occurred at the same level (major or minor), the upper extremity was considered for analysis.

Demographics including age, sex, and admission date were retrieved. The databases have previously been used in population health-related research, and their validity, reliability, and completeness are established elsewhere [16-18]. Saskatchewan resident population from 2006 to 2019 by year, age groups ( $0-49$ years, $50-74$ years, and $75+$ years) and sex (male/female), from the Saskatchewan Bureau of Statistics, was used as denominators to calculate rates [19].

\section{Data analysis}

Saskatchewan's annual LA rates for years 2006 to 2019 were calculated from total cases per yearly Saskatchewan resident population expressed per 100,000. To adjust for the effect of age and sex, a direct standardization method was performed using the 2011 population in Canada as the standard population [20,21]. Rates were standardized by multiplying age group (0-49, 50-74, and $75+$ years) and sex (male/female) specific rates by age and sex-specific weights. Then, a time-trend analysis was conducted to compare trends among population sub-groups.

Joinpoint regression [22] was then performed to identify and quantify significant changes in LA rates and by type (UEA/LEA) and level (major/minor). The regression model was fitted using a grid search method incorporated in the joinpoint software, assuming a constant variance and uncorrelated error term for the model [23]. The ideal number of breakpoints was determined via a permutation test with $p<0.05$ considered statistically significant. Changes in each breakpoint and the full 
range of investigation (2006-2019) were reported as annual percent change (APC) and average annual percent change (AAPC) along with their respective 95\% confidence intervals $(95 \% \mathrm{CI})$.

A negative binomial regression was used to determine differences in temporal LA rate trends between males and females and among age groups $(0-49$ years, $50-74$ years, $75+$ years) [24]. An unadjusted model was fitted between the LA rate and each explanatory variable (age and sex) individually in two separate models (I and II). Then, the year of LA and interaction of year of LA by each explanatory variable (example, age by year and sex by year) were adjusted in each model. Relative rate (RR) and 95\% CI were estimated. Differences in LA rate slopes between explanatory variables (e.g., female vs. male) over time were identified by an interaction $p<0.05$.

\section{Results}

\section{Cases}

Over the 14 years (2006-2019), 5868 LA's were performed in Saskatchewan, of which 4895 (83.4\%) were LEA, and 973 (16.5\%) were UEA. Minor LA predominated for both LEA (2777 minor, 2118 major) and UEA (884 minor, 89 major). More than one LA was identified in 47 hospitalizations eliminating 23 data points representing $0.4 \%$ of the entire study cohort over 14 years which insignificantly impacting our results.

\section{Trends in limb amputation by type (UEA/LEA)}

Figure 1 illustrates a comparison of LEA and UEA trends from 2006 to 2019. Consistently higher rates of LEA $(31.86 \pm 2.85$ per 100,000$)$ than UEA $(5.84 \pm 0.49$ per 100, 000) were observed. The Joinpoint analysis (Table 1) revealed both LEA and UEA insignificantly declined of $0.5 \%$ (AAPC -0.5 [95\% CI -3.8 to 3.0]) and $0.2 \%$ (AAPC -0.2 [95\% CI -1.5 to1.2]) respectively over the entire study period. Further analysis revealed LEA rates significantly increased 3.15\% (APC 3.15 [95\% CI 1.1 to 5.2$])(p<0.05)$ from 2008 to 2017 countered by two insignificant periods of decline (2006-2008 and 2017-2019). In contrast, no break points were identified in the rate of UEA during the study period.

\section{Trends in limb amputation by level (major/minor)}

Figure 2 depicts type (LEA/UEA) and level (major/ minor) of LA trends between 2006 and 2019. The rate of minor UEA was lower than the rate of minor LEA $(5.26 \pm 0.55$ and $18.03 \pm 3.12$ per 100,000 population, respectively; $p<0.001$ ) with limited major UEA sample size precluding comparison. The 14-year rate of major LEA was less than the rate of minor LEA $(13.83 \pm 2.30$; $18.03 \pm 3.12$ respectively; $p<0.001$ ). However, the rate of major LEA exceeded that of minor LEA in years 20062008 with reversal in 2009 and persistence through the remainder of the study period.

Joinpoint analysis (Table 1) revealed minor LEA rates increased 3.9\% over the study period (AAPC 3.9 [95\% CI 2.4 to 5.4$])(p<0.05)$ with no breakpoints while major LEA rates decreased 4.6\% (AAPC -4.6 [95\% CI - 7.6 to - 1.6]) with three break points. From 2010 to 2017 major LEA rates increased $4.2 \%$ (APC 4.2 [95\% CI 0.9 to 7.6]) $(p<0.05)$ countered by a decrease of $11.14 \%$ in $2006-$ 2010 (APC -11.14 [95\% CI -16.4 to -5.6$])(p<0.05)$ and $19.5 \%$ in $2017-2019$ (APC -19.49 [95\% CI -33.5 to

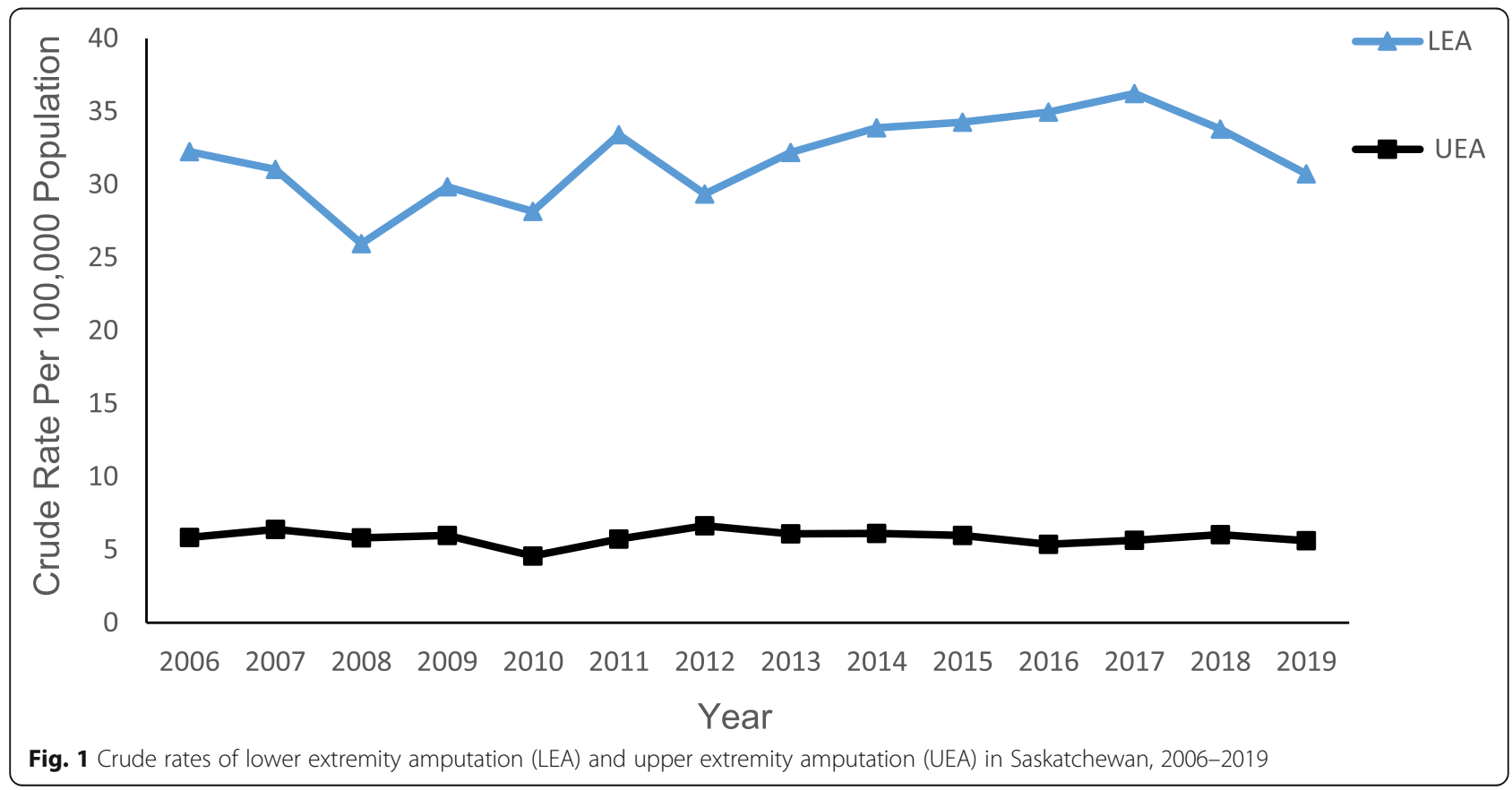


Table 1 Annual Percent Change in lower and upper extremity amputation rate, 2006-2019

\begin{tabular}{llll}
\hline Amputation type/ level & Breakpoints & $\begin{array}{l}\text { APC } \\
\text { (95\% Cl) }\end{array}$ & \multicolumn{1}{c}{$\begin{array}{c}\text { AAPC } \\
\text { (95\% Cl) }\end{array}$} \\
\hline Lower Extremity & $2006-2008$ & $-8.24(-23.6$ to 10.3$)$ & $-0.5(-3.8$ to 3.0$)$ \\
& $2008-2017$ & $3.15^{*}(1.1$ to 5.2$)$ & $-8.02(-23.5$ to 10.5$)$ \\
Upper Extremity & $2017-2019$ & $-0.16(-1.5$ to 1.2$)$ & $-0.2(-1.5$ to 1.2$)$ \\
Upper Extremity Minor & $2006-2019$ & $-0.62(-2.1$ to 0.9$)$ & $-0.6(-2.1$ to 0.9$)$ \\
Lower Extremity Minor & $2006-2019$ & $3.88^{*}(2.4$ to 5.4$)$ & $3.9^{*}(2.4$ to 5.4$)$ \\
Lower Extremity Major & $2006-2019$ & $-11.14^{*}(-16.4$ to -5.6$)$ & $-4.6^{*}(-7.6$ to -1.6$)$ \\
& $2006-2010$ & $4.20^{*}(0.9$ to 7.6$)$ & $-19.49^{*}(-33.5$ to -2.5$)$ \\
\hline
\end{tabular}

APC Annual Percent Change, AAPC Average Annual Percent Change, Cl Confidence Interval

*Indicates a statistically significant breakpoint $p<0.05$

- 2.5]) $(p<0.05)$. Minor UEA rates insignificantly decreased (APC -0.62 [95\% CI -2.1-0.9]) over the entire study period (2006 and 2019) with no breakpoints identified. Too few major UEA occurred to warrant analysis.

\section{Trend in limb amputation by age}

LA rates were higher in those aged $75+$ years compared to those aged $50-74$ and $0-49$ years during the entire study period 2006 to 2019 (Fig. 3).

The unadjusted results in Table 2 revealed that people aged $50-74$ years and $75+$ years were respectively 5.49 (95\% $\mathrm{Cl} 5.08$ to 5.93 ) and 9.10 (95\% Cl 8.45 to 9.80 ) times more likely to experience LA compared to those aged 0-49 years. After adjusting for the year of amputation and the interaction between age and year of amputation, the RR increased to 5.92 (95\% Cl 5.39 to 6.51) and 10.58 (95\% Cl 9.26 to 12.08). In addition, the statistically significant interaction between age and year of amputation $(p=0.007)$ indicates the changes in amputation rate over the 14 years were different among the three age group with an increase in the rate of LA increasing with age.

\section{Trends in limb amputation by sex}

For the 14-year study period (2006-2019) males had significantly higher rates of LA than females $(p<0.001)$

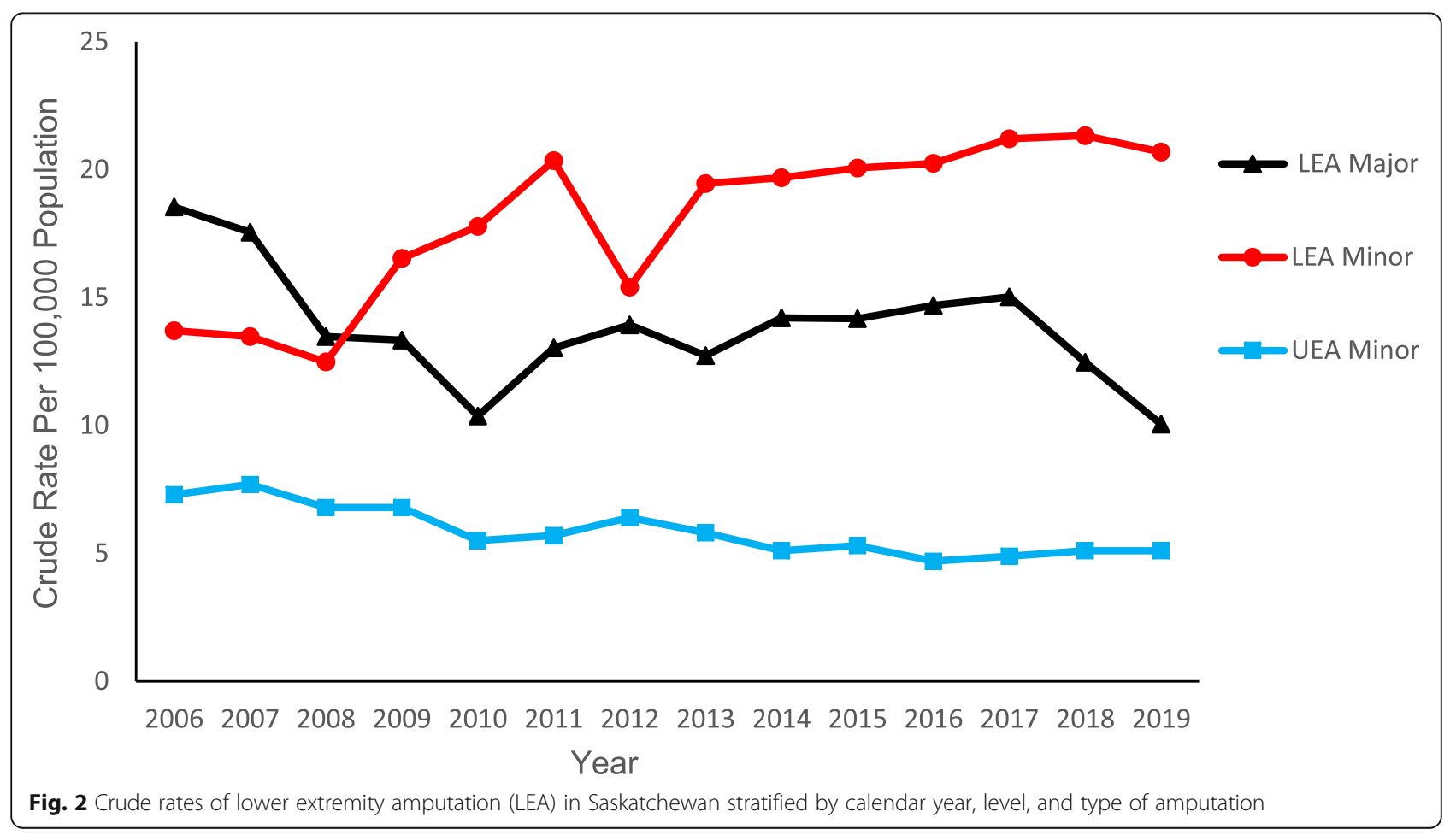




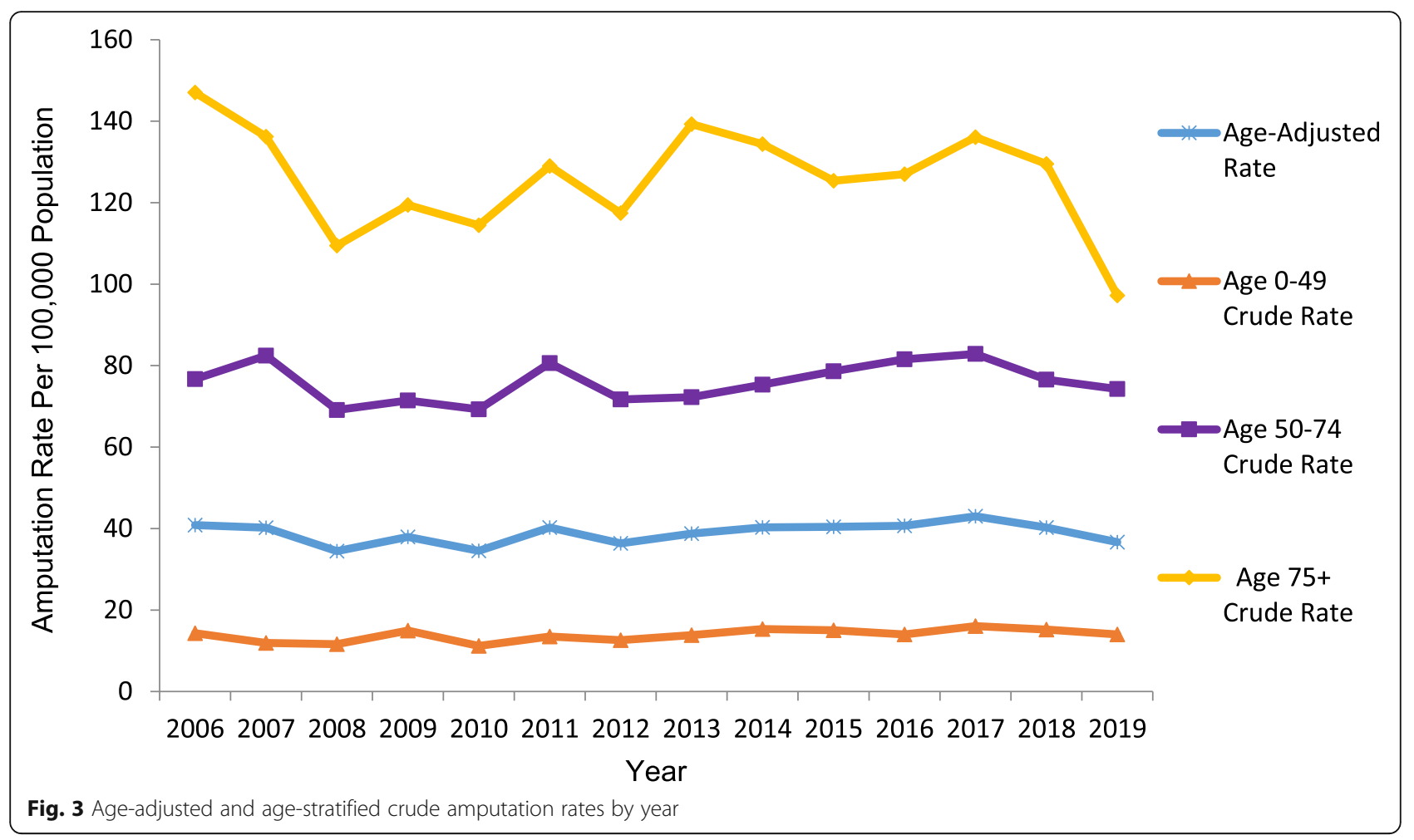

(Fig. 4). The sex-stratified crude rates are consistent with the associations found via the negative binominal regression in Table 2.

The unadjusted model identified males were 2.43 (95\% Cl 2.30 to 2.56) times more likely to undergo LA than females. After adjusting for the year of amputation and sex-by-year of amputation interaction, the RR decreased to 2.24 ( $95 \% \mathrm{Cl} 1.99$ to 2.51 ) however, the sex-by-year of amputation interaction was not statistically significant $(p=0.120)$, suggesting LA rate did not differ over time by sex.

\section{Age-and-sex adjusted rates}

The average age- and sex-adjusted LA rates from 2006 to 2019 were 38.91 and 38.35 per 100,000 population, respectively. Despite the variable trends observed in both crude age- and -sex stratified rates over the study period, after controlling for age and sex, the age- and

Table 2 Unadjusted and adjusted relative rates for amputations among population groups

\begin{tabular}{|c|c|c|c|c|c|c|c|c|}
\hline \multirow[t]{2}{*}{ Variables } & \multicolumn{4}{|c|}{ Unadjusted } & \multicolumn{4}{|c|}{ Adjusted } \\
\hline & Coef. & RR & $95 \% \mathrm{Cl}$ & $\overline{P \text {-value }}$ & Coef. & RR & $95 \% \mathrm{Cl}$ & $P$-value \\
\hline \multicolumn{9}{|l|}{ Model I } \\
\hline \multicolumn{9}{|l|}{ Age/years } \\
\hline $0-49$ & & 1.00 & & & & 1.00 & & \\
\hline $50-74$ & 1.703 & 5.49 & $(5.08-5.93)$ & $<0.001$ & 1.779 & 5.92 & $(5.39-6.51)$ & $<0.001$ \\
\hline $75+$ & 2.209 & 9.10 & $(8.45-9.80)$ & $<0.001$ & 2.359 & 10.58 & $(9.26-12.08)$ & $<0.001$ \\
\hline Year & -0.001 & & & 0.938 & 0.024 & & & 0.012 \\
\hline Age and Year Int* & & & & & -0.010 & & & 0.007 \\
\hline \multicolumn{9}{|l|}{ Model II } \\
\hline \multicolumn{9}{|l|}{ Sex } \\
\hline Female & & 1.00 & & & & 1.00 & & \\
\hline Male & 0.886 & 2.43 & $(2.30-2.56)$ & $<0.001$ & 0.806 & 2.24 & $(1.99-2.51)$ & $<0.001$ \\
\hline Year & 0.005 & & & 0.565 & -0.013 & & & 0.271 \\
\hline Sex and Year Int* & & & & & 0.011 & & & 0.120 \\
\hline
\end{tabular}




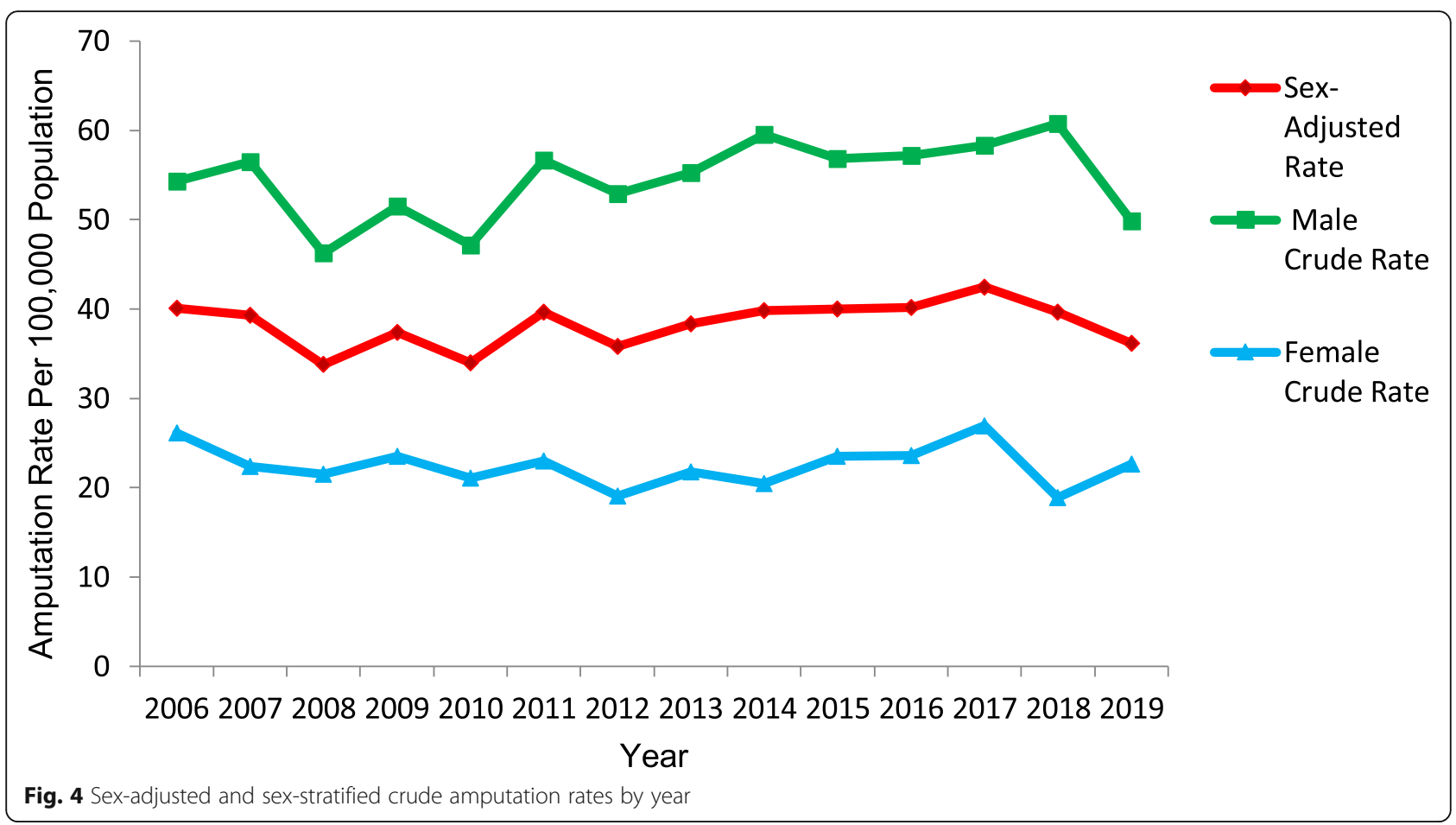

-sex adjusted rates remained stable especially between 2012 and 2016-2017, although there were fluctuations in the crude rates over the study period. The decline observed in the age-adjusted rate from 2017 to 2019 could be attributed to the change in the population base (more older people in 2017-2019) of those aged 50+ years.

\section{Discussion}

This is the first study to report changes in limb amputation rates considering all amputations by type, level, sex and age in Saskatchewan from 2006 to 2019 irrespective of cause of amputation. We chose to do this because limiting the cohort to the most prevalent cause and level of amputation limits the understanding of societal impact. We found the overall rate of LA (both UEA and LEA) remained stable over the 14-year study period however fluctuations were identified in the rate of LEA during the study period. LEA significantly increased 3.15\% (APC 3.15 [95\% CI 1.1 to 5.2]) $(p<0.05)$ from 2008 to 2017 but this was countered by two periods of insignificant but impactful decline in LEA rate (20062008 and 2017-2019).

An earlier published Canadian study found declining trends in LEA rates at national and provincial levels over a 6 year period between 2006 and 2011 [6]. We performed a joinpont analysis on Imam et al.'s published age-adjusted rate data and found that Canada's national LEA rate declined by $1.6 \%$, Manitoba declined by $0.3 \%$, Nova Scotia declined by $1.3 \%$, Ontario declined by $2.1 \%$, Newfoundland declined by $3.9 \%$, and Saskatchewan declined by $2.4 \%$ [6]. In contrast, a $1.3 \%$ increase in the rate of LEA was identified in Alberta, a province with a similar sociodemographic profile as Saskatchewan during the same time interval [6]. Our study identified that expanding the data set to 2019 alters this trend revealing an insignificant $(0.5 \%)$ LEA rate of decline.

Our findings were also compared globally. Li et al. (2012) reported a decrease in the discharge rate of nontraumatic LEA performed in the United States from 11.2 per 1000 persons with diabetes in 1996 to 3.9 in 2008 while the rate of LEA did not change in persons without diabetes [25]. Geiss et al. (2019) also reported a significant decrease in the hospitalization rate of nontraumatic LEA performed in the United States from 5.38 per 1000 adults with diabetes in 2000 to 3.07 in 2009 but this decline rebounded to 4.62 in 2015 [26]. Unlike Li (2012), Geiss et al. found a decline in nontraumatic LEA in adults without diabetes from 0.23 per 1000 in 2000 to 0.18 in 2015 [26]. The reported trends illustrate the importance of examining LA data over long periods of time and the need for further analyses to identify external factors influential to these rates.

The low incidence of UEA found in our cohort was expected and indicates trends in the overall LA rate are largely due to the influence of LEA. This imbalance is in line with other studies worldwide [27, 28] and mainly due to differences in the leading causes of LEA and UEA $[6,29,30]$. Vascular disease, specifically diabetes is the leading cause of LEA [31] responsible for more than $65 \%$ of LEA in Canada from 2006 to 2011 [6] while 
trauma accounts for $80-90 \%$ of all UEA [29, 30]. Our study cohort, specific data reported elsewhere, had a similar causal distribution with diabetes identified as the predominant (54.1-81.5\%) predisposing factor, followed by peripheral vascular disease not associated with diabetes $(4.2-16.3 \%)$ and then trauma $(4.3-8.7 \%)$ [32].

Further analysis of type of amputation revealed most UEA were minor (distal to the wrist) with major (through and proximal to the wrist) UEA rates not assessed because of limited sample size. The predominance of minor UEA is supported by Ziegler-Graham's who reported minor UEA accounted for $92 \%$ of the 541,000 UEA performed in the US in 2005 [29].

Like UEA, most LEA were minor (distal to the ankle). Our finding that LEA insignificantly declined (AAPC - 0.5 [95\% CI -3.8 to 3.0]) from 2006 to 2019 was disappointing but we were encouraged by the 3.9\% (AAPC 3.9 [95\% CI 2.4 to 5.4] $)(p<0.05)$ increase in minor LEA associated with a decline of $4.6 \%$ (AAPC -4.6 [95\% CI -7.5 to -1.6$]$ ) $(p<0.05)$ in major (through or proximal to the ankle) LEA rate over the study period. Fluctuations in major LEA rate nearly corresponded with fluctuations in the overall LEA rate with one period of rising rates from 2010 to 2017 (APC 4.2 [95\% CI 0.9 to 7.6]) $(p<0.05)$ countered by two periods of decline 2006-2010 (APC -11.14 [95\% CI - 16.4 to - 5.6]) $(p<0.05)$ and 2017-2019 (APC -19.49 [95\% CI -33.5 to -2.5$])(p<0.05)$. Our findings are supported by other studies that report increased rates of minor LEA over the past two decades [26, 33-35]. Geiss et al. (2019) identified a $62 \%$ increase in the rate of nontraumatic minor LEA but, in contrast to our findings, they reported a $29 \%$ increase in nontraumatic major LEA between 2009 and 2015 [26]. The increase in minor LEA rates may be reflective a paradigm shift in the surgical care of people with foot ulcers with minor, often repeated LEA performed in efforts to save the limb and maintain a functional foot on which to walk [36]. The increase in minor LEA may shift the need to orthotic intervention such as foot plates and toe fillers, as opposed to prosthetic intervention after LA [37].

Our finding that males were twice as likely to undergo LA than females ( $R R=2.24$ [95\% CI 1.99 to 2.51]) is consistent with the literature $[6,25,26,38]$. The higher rate of LA among men, as evidenced by the current study's crude rate estimates was consistent with Canada's national amputation rate pattern for 2006-2011 [6]. Internationally, a study examining German national discharge abstract data found a significant decrease in the rate of LLA for both men and women from 2005 to 2015 , with men experiencing less of a decrease $(-2.6 \%)$ than women $(-25 \%)$ [38]. This decline in overall LLA rate was attributed more higher-level initial amputations, thus decreasing the need for revision preocedures often associated with minor amputation [38].
Our finding that older persons are disproportionately affected by LA is also consistent with the literature [39]. We found persons aged $50-74$ years and $75+$ years were respectively $5.9(\mathrm{RR}=5.92[95 \% \mathrm{Cl} 5.39$ to 6.51$])$ and $10.6(\mathrm{RR}=10.58[95 \% \mathrm{Cl} 9.26$ to 12.08$])$ times more likely to undergo LA than those aged $0-49$ years $(p<$ $0.001)$. We also found the rate of LA increased for persons $50+$ years of age over the study period.

Aziz et al. found age 60+ years to be a significant predictor of amputation in people with diabetic foot infections [39]. Two diverse statistical methods applied to the current study data showed that age, especially those aged 50-74 years and $75+$ years was a stronger amputation rate driver. This could in part be attributed to accelerated risk of developing vascular complications as people live longer with chronic vascualar diseases, such as diabetes $[13,40]$. Since diabetes was the major predictive factor for LA in our cohort [34] our findings give rise to the well documented need for pro-active diabetes care. Data from Diabetes Canada [41] and the Government of Canada-Action for Seniors Report [42] contribute to future concerns. Diabetes Canada reports that in Saskatchewan, in 2018, the largest group of persons with diabetes were 60-74 years of age, followed by persons $75+$ years of age [41]. The prevalence of diabetes is expected to increase from 2015 reported 9.3 to $12.1 \%$ of the population by 2025 [43]. Further, the government of Canada predicts a rise in the percentage of older Canadians, with life expectancy for both men and women also predicted to rise [42]. Collectively, these data will likely shift the currently declining trend in amputation rate in Saskatchewan.

\section{Strengths and limitations}

This study used diverse statistical methods to thoroughly assess and elucidate the influence of type, level, age and sex on amputation rate in the province. The study was limited by UEA inadequate samples.

\section{Conclusion}

Our broader examination of the epidemiology of LA, independent of cause, identified that rate of LA (both UEA and LEA) remained stable over the 14-year study period in Saskatchewan, Canada. Not surprising were the findings that the rate of male LA more than twice outnumbered that of female, that LEA thrice outnumbered UEA and that LA increased with increasing age. Interesting was the finding that overall LEA rate was largely driven by the rate of major LEA. In summary, we found a declining rate of major LEA concomitant with an increasing rate of minor LEA with a rising age of persons affected by LA in Saskatchewan from 2006 to 2019. Further research is needed to determine if these findings are due to medical and/or social interventions adopted over 
the past two decades to counter complications of vascular disease and to determine if changing major and minor LA ratios alters orthotic and prosthetic prescription.

\section{Abbreviations}

LA: Limb amputation; DM: Diabetes mellitus; DAD: Discharge abstract disease; APC: Annual percent change; AAPC: Average annual percent change; Cl: Confidence interval; RR: Relative rate; LEA: Lower extremity amputation; UEA: Upper extremity amputation; CCl: Canadian Classification of Health Intervention

\section{Supplementary Information}

The online version contains supplementary material available at https://doi. org/10.1186/s13690-021-00759-1.

\section{Additional file 1.}

\section{Acknowledgments}

The authors would like to express our gratitude to the Saskatchewan Amputee Patient-Oriented Research Team (PORT) for their invaluable inputs in drafting this manuscript.

\section{Disclaimer}

This study is based in part on de-identified data provided by the Saskatchewan Ministry of Health and eHealth Saskatchewan. The interpretation and conclusions contained herein do not necessarily represent those of the Government of Saskatchewan, the Saskatchewan Ministry of Health, or eHealth Saskatchewan.

\section{Authors' contribution}

SKE and AZL conducted the literature reviews. SKE, AGL, DK, and AZL conceptualized and designed the study and drafted the manuscript. SKE and AZL secured the study data and performed the analyses; SKE, AGL, DK, and AZL interpreted the results. DK provided critical revision to the manuscript. All authors have read and approved the final copy.

\section{Funding}

This study was supported in part by the University of Saskatchewan Centre for Patient-Oriented Research through funding from the awards of postdoc toral fellows interested in conducting patient-oriented health research. This award has no award number.

\section{Availability of data and materials}

The datasets used and/or analysed during the current study are available from the corresponding author on reasonable request.

\section{Declarations}

Ethics approval and consent to participate

Ethics approval was secured for this study from the University of Saskatchewan Biomedical Ethics Board (U of S \# Bio 1590). Consent to participate is not applicable to this study.

\section{Consent for publication}

Not applicable.

\section{Competing interests}

None declared.

\section{Author details}

'School of Rehabilitation Science, University of Saskatchewan, Health Science Building, E-Wing, Suite 3400, 3rd Floor, 104 Clinic Place, Saskatoon, SK S7N 2Z4, Canada. ${ }^{2}$ Department of Surgery, University of Saskatchewan College of Medicine, Saskatoon, Canada. ${ }^{3}$ Section of Vascular Surgery, Regina Qu'Appelle Health Region, University of Saskatchewan, Regina, Canada. ${ }^{4}$ Department of Physical Medicine and Rehabilitation, University of Saskatchewan, Saskatoon, SK, Canada.
Received: 12 April 2021 Accepted: 11 December 2021

Published online: 04 January 2022

\section{References}

1. Palli S, Gunnarsson C, Kotlarz H, Martinsen BJ, Zhao R, Rizzo JA. Impact of a limb salvage program on the economic burden of amputation in the United States. Value Health. 2016;19(3):A45.

2. HealthLinkBC [Internet]. Leg amputation. [cited 3 December 2020]. Available from: https:/www.healthlinkbc.ca/health-topics/ue4791abc.

3. Sahu A, Sagar R, Sarkar S, Sagar S. Psychological effects of amputation: a review of studies from India. Ind Psychiatry J. 2016;25(1):4.

4. Çamur S, Batıbay SG, Bayram S. Effect of lower extremity amputation on caregiving burden in caregivers of patients with diabetic foot: prospective cohort study. Int Wound J. 2020;17(4):890-6.

5. Rack A, Hofmann GO. Psychological and social impact of lower limb amputation following trauma-a retrospective evaluation of the amputation moment. Aktuelle Traumatol. 2003;33(5):228-35.

6. Imam B, Miller WC, Finlayson HC, Eng JJ, Jarus T. Incidence of lower limb amputation in Canada. Can J Public Health. 2017;108(4):374-80.

7. Humphries MD, Brunson A, Hedayati N, Romano P, Melnkow J. Amputation risk in patients with diabetes mellitus and peripheral artery disease using statewide data. Ann Vasc Surg. 2016:30:123-31.

8. Diabetes Canada [Internet]. Diabetes in Canada. [cited 4 December 2020]. Available from: https://www.diabetes.ca/DiabetesCanadaWebsite/media/A bout-Diabetes/Diabetes\%20Charter/2019-Backgrounder-Canada.pdf.

9. Diabetes Canada [Internet]. Diabetes in Saskatchewan. [cited 4 December 2020]. Available from: https://www.diabetes.ca/DiabetesCanadaWebsite/ media/About-Diabetes/Diabetes\%20Charter/2018-Backgrounder-Saska tchewan_JK_AB-edited-13-March-2018.pdf.

10. Diabetes Canada [Internet]. [cited 24 January 2021]. Available from: https:// www.diabetes.ca/media-room/press-releases/one-in-three-canadians-isliving-with-diabetes-or-prediabetes,-yet-knowledge-of-risk-and-complicatio.

11. Centers for Disease Control, Prevention (US), Division of Surveillance \& Epidemiology. Systems Operation and Information Branch, 1995. Manual of procedures for the reporting of nationally notifiable diseases to CDC. US Department of Health and Human Services, Public Health Service, Centers for Disease Control and Prevention.

12. Birnbaum D, Ely JW, Dawson JD, Lemke JH, Rosenberg J. An introduction to time-trend analysis. Infect Control Hosp Epidemiol. 1997;18(4):267-74.

13. Buckley CM, O'Farrell A, Canavan RJ, Lynch AD, Davida V, Bradley CP, et al. Trends in the incidence of lower extremity amputations in people with and without diabetes over a five-year period in the Republic of Ireland. PLoS One. 2012;7(7):e41492.

14. Canadian Institute for Health Information [Internet]. Canadian Classification of Health Interventions. 2015. [cited 24 May 2020]. Available from: https:// www.cihi.ca/sites/default/files/cci_volume_four_2015 en_0.pdf.

15. Ephraim PL, Dillingham TR, Sector M, Pezzin LE, MacKenzie EJ. Epidemiology of limb loss and congenital limb deficiency: a review of the literature. Arch Phys Med Rehabil. 2003;84(5):747-61.

16. Edouard L, Rawson NS. Reliability of the recording of hysterectomy in the Saskatchewan health care system. BJOG Int J Obstet Gynaecol. 1996;103(9): 891-7.

17. Liu L, Reeder B, Shuaib A, Mazagri R. Validity of stroke diagnosis on hospital discharge records in Saskatchewan, Canada: implications for stroke surveillance. Cerebrovasc Dis. 1999:9(4):224-30.

18. Rawson NS, D'Arcy C. Assessing the validity of diagnostic information in administrative health care utilization data: experience in Saskatchewan. Pharmacoepidemiol Drug Saf. 1998;7(6):389-98.

19. Saskatchewan Bureau of Statistics. [cited May 24, 2020]. Available from: https:/www.saskatchewan.ca/government/government-data/bureau-of-sta tistics/population-and-census.

20. Lee WC, Liaw YP. Optimal weighting systems for direct age-adjustment of vital rates. Stat Med. 1999:18(19):2645-54.

21. Statistics Canada [Internet]. Population estimates on July 1st, by age and sex. [Accessed on July 19, 2020]. Available from: https://www150.statcan.gc. ca/t1/tbl1/en/cv.action?pid=1710000501\#timeframe.

22. Kim HJ, Fay MP, Feuer EJ, Midthune DN. Permutation tests for joinpoint regression with applications to cancer rates. Stat Med. 2000;19(3):335-51.

23. National Cancer Institute [Internet]. Surveillance Research Program. Heteroscedastic Error Options 2020 [cited December 10, 2020]. Available from: https://surveillance.cancer.gov/joinpoint/Joinpoint_Help_4.8.0.1.pdf. 
24. Hilbe JM. Negative binomial regression. Cambridge: Cambridge University Press; 2011.

25. Li Y, Burrows NR, Gregg EW, Albright A, Geiss LS. Declining rates of hospitalization for nontraumatic lower-extremity amputation in the diabetic population aged 40 years or older: US, 1988-2008. Diabetes Care. 2012; 35(2):273-7.

26. Geiss LS, Li Y, Hora I, Albright A, Rolka D, Gregg EW. Resurgence of diabetes-related nontraumatic lower-extremity amputation in the young and middle-aged adult US population. Diabetes Care. 2019;42(1):50-4.

27. Chalya PL, Mabula JB, Dass RM, Ngayomela IH, Chandika AB, Mbelenge $N$, et al. Major limb amputations: a tertiary hospital experience in northwestern Tanzania. J Orthop Surg Res. 2012;7(1):1-6. (former 25).

28. Kim YC, Park Cl, Kim DY, Kim TS, Shin JC. Statistical analysis of amputations and trends in Korea. Prosthetics Orthot Int. 1996;20(2):88-95. (former 26).

29. Ziegler-Graham K, MacKenzie EJ, Ephraim PL, Travison TG, Brookmeyer R. Estimating the prevalence of limb loss in the United States: 2005 to 2050. Arch Phys Med Rehabil. 2008;89(3):422-9.

30. Maduri P, Akhondi H. Upper limb amputation. StatPearls [Internet]. 2020 [cited February 25, 2021]. Available from: https://www.ncbi.nIm.nih.gov/ books/NBK540962/.

31. Perkins BA. Sounding the alarm on rising diabetes-related amputations. CMAJ. 2019:191(35):E953-4.

32. Essien SK, Linassi G, Larocque M, Zucker-Levin A. Incidence and trends of limb amputation in first nations and general population in Saskatchewan, 2006-2019. PLoS One. 2021;16(7):e0254543.

33. Gurney JK, Stanley J, York S, Rosenbaum D, Sarfati D. Risk of lower limb amputation in a national prevalent cohort of patients with diabetes. Diabetologia. 2018;61(3):626-35.

34. Kröger K, Berg C, Santosa F, Malyar N, Reinecke H. Lower limb amputation in Germany: an analysis of data from the German Federal Statistical Office between 2005 and 2014. Dtsch Arztebl Int. 2017;114(8):130. (former 32).

35. Agarwal S, Sud K, Shishehbor MH. Nationwide trends of hospital admission and outcomes among critical limb ischemia patients: from 2003-2011. J Am Coll Cardiol. 2016;67(16):1901-13.

36. Mayo Clinic [Internet]. Amputation and diabetes: How to protect your feet. [cited December 25 2020]. Available from: https://www.mayoclinic.org/disea ses-conditions/diabetes/in-depth/amputation-and-diabetes/art-20048262.

37. Balduzzi G, De Giglio R, Masserini B, Formenti I, Lodigiani S, Mondello T, et al. Effectiveness, safety, and acceptance of an interim orthosis in patients with diabetes in the immediate postoperative chopart surgery. Int J Low Extrem Wounds. 2021:15347346211023041.

38. Spoden M, Nimptsch U, Mansky T. Amputation rates of the lower limb by amputation level-observational study using German national hospital discharge data from 2005 to 2015. BMC Health Serv Res. 2019;19(1):1-9.

39. Aziz Z, Lin WK, Nather A, Huak CY. Predictive factors for lower extremity amputations in diabetic foot infections. Diabet Foot Ankle. 2011;2(1):7463.

40. Fortington LV, Rommers GM, Postema K, van Netten JJ, Geertzen JH, Dijkstra PU. Lower limb amputation in northern Netherlands: unchanged incidence from 1991-1992 to 2003-2004. Prosthetics Orthot Int. 2013;37(4):305-10.

41. Diabetes Canada 2018. [cited 24 May 2020]. Available from: https://umw.diabetes.ca/ DiabetesCanadaWebsite/media/Advocacy-and-Policy/Advocacy\%20Reports/ Economic-Impact-of-Offloading-Devices-on-DFU-Costs-in-SK-_FINAL.pdf.

42. Government of Canada. Action for seniors report 2014 [cited 13 June 2020]. Available from: https://www.canada.ca/en/employment-social-development/ programs/seniors-action-report.html.

43. Houlden LR. Diabetes Canada Clinical Practice Guidelines Expert Committee. Diabetes Canada 2018 clinical practice guidelines for the prevention and management of diabetes in Canada. Can J Diabetes. 2018;42(Suppl 1):S1-325.

\section{Publisher's Note}

Springer Nature remains neutral with regard to jurisdictional claims in published maps and institutional affiliations.

Ready to submit your research? Choose BMC and benefit from:

- fast, convenient online submission

- thorough peer review by experienced researchers in your field

- rapid publication on acceptance

- support for research data, including large and complex data types

- gold Open Access which fosters wider collaboration and increased citations

- maximum visibility for your research: over $100 \mathrm{M}$ website views per year

At BMC, research is always in progress.

Learn more biomedcentral.com/submissions 